KEMBALINYA SURGA FIRDAUS: MENILIK KEMERDEKAAN INDONESIA

MELALUI PANDANGAN 'ALI AḤMAD BĀKATHĪR DALAM DRAMA 'AUDAT

\title{
AL-FIRDAUS
}

\section{Mohammad Rokib}

Universitas Negeri Surabaya

Email: mohammadrokib@unesa.ac.id

\begin{abstract}
Abstrak
Ali Ahmad Bākathìr adalah dramawan produktif, novelis, dan penyair abad ke-20. Dia menulis hampir lima puluh karya sastra dan lebih dari tiga puluh drama dalam yang mengambangkan karakter Islam. Karya-karyanya berusaha untuk membangun nilai-nilai Islam dan tradisi yang terjadi dalam masyarakat Islam. Meskipun karya-karyanya berkontribusi sangat besar terhadap sastra Arab dan Islam, Bākathīr telah menerima kurangnya perhatian dari para sarjana baik di dunia Islam dan di dunia non-Islam. Makalah ini membahas upaya Muslim dalam memperoleh kemerdekaan nasional pada karya-karya sastra dari Bākathīr, terutama pada konsep nasionalisme di Indonesia. Dalam proses mendapatkan kemerdekaan nasional, tokoh Indonesia biasanya memanfaatkan paradigma nasionalisme melalui kata-kata dari dialog. Dalam tulisan ini, kami berpendapat bahwa Bākathīr drama berjudul 'Audat al-Firdaus mengandung semangat nasionalisme untuk memperoleh kemerdekaan.
\end{abstract}

Kata Kunci: drama, nasionalisme, kemerdekaan.

\begin{abstract}
Ali Ahmad Bākathìr was a prolific Arab playwright, novelist and poet of the $20^{\text {th }}$ Century. He wrote almost fifty literary works and more than thirty plays in Arabic which developed Islamic character in Arabic literature. His works sought to establish Islamic values and traditions that occurred in Islamic societies. Although his works contributed immensely to the Arabic and Islamic literature, Bākathìr has received lack of attention from scholars both in Islamic world and in non-Islamic world. This paper explores the Muslim effort in acquiring national independence on the literary works of Bākathir, particularly on the concept of nationalism. In the process of acquiring national independence, Indonesia's figures usually utilized the paradigm of nationalism through words of dialog. The words of figure that
\end{abstract}


referred to nationalism will be discussed. In this paper, we argue that Bākathïr literary work's 'Audat al-Firdaus contains the spirit of nationalism for gaining independence.

Keywords: playwright, nasionalism, independence.

\section{PENDAHULUAN}

Ali ahmad Bākathīr adalah salah seorang penulis Arab yang prolifik (subur) dalam menghasilkan karya sastra. Dia adalah satu di antara sastrawan Arab yang menulis drama-drama Arab. Hampir seluruh karyakaryanya menonjolkan nuansa keislaman yang memberi kontribusi penting bagi perkembangan studi sastra Arab abad ke 20. Dibanding dengan penulis atau sastrawan Arab lain seperti Taha Husayn, Taufiq Hakim, dan Naguib Mahfouz yang mendapatkan perhatian dari banyak peneliti, Bākathīr kurang mendapatkan perhatian.

Dalam karya-karyanya, Bākathīr secara kuat menampakkan simbolsimbol Islam sebagai ekspresi dari keyakinan dan lingkup sosial budaya yang dimilikinya. Dia nampak berusaha menyuguhkan ajaran Islam melalui karya sastra yang ditulis baik itu ajaran-ajaran yang bersifat wajib bagi umat Islam maupun kehidupan sehari-hari dalam masyarakat Islam. Secara esensial, beberapa karya Bākathīr bahkan menyuguhkan beberapa ayat alQur'an sebagai simbol nilai-nilai Islam yang berusaha ditonjolkan sebagai media dakwah (Hassim, 2009).

Salah satu karya di antara beberapa karya Bākathīr yang memotret problematika kehidupan umat Islam Indonesia adalah drama 'Audat alFirdaus, sebuah drama yang mengisahkan perjuangan tokoh Indonesia dalam merebut kemerdekaan. Dalam karya ini, Bākathīr berusaha mengemukakan pendapat bahwa kemerdekaan Indonesia adalah hasil dari 160 | ISSN: 22477-5150 http://journal.unesa.ac.id/index.php/jpi 
perjuangan bangsa Indonesia sendiri dan bukan hadiah dari sekutu maupun Jepang sebagaimana yang diklaim Jepang. Dalam dialog-dialog yang diperankan oleh para tokoh drama, terlihat bagaimana para pejuang Indonesia berusaha merebut kemerdekaan melalui cara mereka baik secara fisik maupun secara politik. Cara-cara perjuangan fisik ditampilkan melalui dialog-dialog pengikut Sahrir sementara cara-cara politik ditampilkan melalui representasi pengikut Soekarno.

Dalam proses memperoleh kemerdekaan tersebut, Bākathīr menunjukkan pembentukan nasionalisme dalam diri para tokoh pejuang Indonesia. Nasionalisme yang dimunculkan melalui aktor-aktor drama memperlihatkan terjadinya visi kemerdekaan yang bebas dari kontrol penjajah untuk menciptakan suatu identitas otonom. Selain itu, dalam drama ini juga ditampilkan bagaimana nasionalisme diwujudkan dalam usaha keluar dari pelecehan dan tindakan-tindakan semena-mena atau tirani penjajah seperti pemerkosaan para gadis lokal (Indonesia).

Tulisan ini berusaha melihat praktik-praktik nasionalisme dalam proses perebutan kemerdekaan. Nasionalisme dilihat sebagai suatu upaya pembangkitan tindakan-tindakan afiliasi untuk mengumpulkan kelompokkelompok yang beraneka ragam di bawah satu simbol entitas politik, pemerintahan, dan ekonomi sebuah bangsa (Lo dan Gilbert dalam Yulia Nasrul Latifi dan Faruk, 2005: 25). Berangkat dari kerangka pikir nasionalisme tersebut, nasionalisme dalam drama 'Audat al-Firdaus dipandang dalam kerangka respons yang dihasilkan oleh negara dunia ketiga dalam usaha penolakan kontrol imperial dalam masyarakat terjajah seperti Indonesia. Kerangka pikir tersebut mengimplikasikan cara-cara 
deskriptif dalam penelitian yang menyajikan data dan menganalisisnya dalam konteks kajian poskolonial.

\section{PEMBAHASAN}

Ali Ahmad Bākathīr adalah seorang novelis, penyair, sekaligus penulis drama terkenal asal Indonesia. Karya-karyanya banyak dibaca masyarakat Mesir dan negara-negara Timur Tengah lainnya karena dia menetap dan mengembangkan karier intelektualnya di Mesir. Dalam ranah sejarah sastra Arab, dia ditempatkan sebagai sastrawan modern, satu angkatan dengan sastrawan tersohor Mesir, Naguib Mahfouz.

Kiprahnya di bidang sastra meninggalkan catatan tersendiri bagi masyarakat Arab. Bākathīr adalah orang yang pertama menulis opera berbahasa Arab secara fasih. Di dunia seni drama, dia adalah penulis drama berbahasa Arab dalam bentuk puisi yang pertama kali. Dia juga pelopor drama bertema Palestina. Salah satu karyanya, epos Umar bin Khathab (al-Malhamah al-Islamiyyah al-Kubrâ), merupakan drama terpanjang kedua di dunia setelah epos tentang perang Napoleon karya Thomas Hardy.

Bākathīr lahir di Surabaya, 21 Desember 1910. Dia keturunan Arab Hadramaut. Saat usia 10 tahun, dia dibawa ayahnya pulang ke Hadramaut, Yaman. Ayahnya menghendaki agar Bākathīr mendapat pendidikan Arab dan Islam. Di tanah leluhurnya itu dia dimasukkan ke Madrasah anNahdah. Dia belajar ilmu-ilmu agama dan bahasa Arab di bawah asuhan seorang qadi, penyair, dan ahli bahasa Arab ternama saat itu, Syekh Muhammad bin Muhammad Bākathīr. Di usia yang masih belia, keahliannya menulis sastra sudah terlihat. Pada usia 13 tahun dia mulai pandai menciptakan syair (Badawi, 1987: 112-25). 
Kehidupan Bākathīr selanjutnya banyak dijalani dengan berpindahpindah. Setelah menjalani masa remaja di Surabaya, Indonesia, dia pindah ke negara nenek-moyangnya, Hadramaut, dan pindah ke Aden. Perpindahan itu disebabkan kesedihan yang mendalam. Istrinya meninggal dunia tidak lama setelah mereka menikah. Dari Aden dia pindah ke Somalia, Habasyah, dan kemudian menetap agak lama di Hijaz (Arab Saudi). Di tanah Hijaz ini, dia mengarang syair panjang yang diberi judul Nadzām al-Burdah. Dia juga menulis drama pertamanya, Hamman (Fî bilâd al-Ahqâf). Setelah lama menetap di Hijaz, Bākathīr pindah ke Mesir. Di sini dia masuk ke Universitas Fuad I (Cairo University) Fakultas Sastra, jurusan Bahasa Inggris. Bidang yang dipelajari ini, memberi kesempatan baginya untuk mempelajari karya-karya sastra dari luar Arab, termasuk Romeo-Julliet, karya Shakespeare. Dia juga sempat menerjemahkannya ke dalam bahasa Arab berbentuk puisi bebas. Bākathīr juga telah menerjemahkan karya-karya Shakespeare dalam usianya yang relatif muda. la menerjemahkan "Romeo dan Juliet" pada tahun 1937 dalam bentuk syair dan termasuk tokoh pertama yang memasukkan aliran syair moderen dalam satra Arab kontemporer.

Bākathīr telah mempersembahkan tidak sedikit karya sastra yang terkait erat dengan nilai-nilai Islam, sejarah Islam dan tokoh-tokoh Islam yang memiliki peran dalam persistiwa-peristiwa besar. Dia termasuk sastrawan yang turut serta dalam mendirikan "Lajnatun Nasyr Lil Jami'iyin" atau Komite Penerbitan Untuk Universitas di Mesir bersama dengan tokoh-tokoh sastrawan terkemuka Mesir Abdul Hamid Jaudah As Sahhar, Naguib Mahfouz, Sayyid Qutb, dan Muhammad Abdul Halim Abdullah, yang berperan mencetak dan menerbitkan buku-buku sastra serta buku- 
buku sekolah dan memiliki penerbit "Maktabah Misr" di kawasan alFagallah.

Karangan lain Bākathīr yang terkenal adalah "Wa Islamahu" yang dicetak berulang-ulang dan menjadi teks wajib bagi sekolah-sekolah menengah di Mesir selama bertahun-tahun. Kisah ini menggambarkan era yang unik dari sejarah Islam dan kegigihan Islam dalm menghadapi agresi Tatar. Cairnya sektarian, nasionalisme, ras dan memunculkan tokoh Islam yang mampu menaklukkan tantangan dan pengkhianatan. Setelah itu ia menulis kisah "Sirah Syuja'" yang hampir mirip dengan buku sebelumnya. Di samping menulis karya-karya teater islami kecil dalam satu atau dua babak yang khusus ia tulis untuk majalah-majalah mingguan dan bulanan.

Di antara karya-karya sastra Bākathīr, lebih dari tiga puluh karya sastra drama telah ditulis. Tema yang diusung dalam karya drama Bākathīr tidak lepas dari tema sejarah, legenda dan folklor (Starkey, 2006: 186). Salah satu dari tema drama sejarah adalah "Audat al-Firdaus". Drama ini mengisahkan tentang proses sejarah perjuangan kemerdekaan Indonesia. Dalam semangat drama, Bākathīr seolah berusaha ingin menguatkan bahwa kemerdekaan bangsa Indonesia adalah hasil dari perjuangan para pejuang pribumi, bukan sebagai hadiah dari sekutu yang saat itu berhasil mengusir Jepang dari Indonesia.

\section{Drama 'Audat al-Firdaus}

'Audat al-Firdaus diperankan oleh tiga belas aktor. Adapun tiga belas aktor tersebut adalah Sulaiman (pemuda pengikut Sutan Syahrir), Majid (pengikut Sukarno sebagai petugas keamanan), Zainah (kekasih Sulaiman, saudara kandung Majid), Aisyah (saudara kandung Sulaiman), Hamidah (ibu Sulaiman dan Aisyah), Haji Abdul Karim (ayah Sulaiman dan Aisyah), 
Otih (pembantu Abdul Karim), Izzuddin (pimpinan perlawanan rahasia terhadap pendudukan Jepang), Sutan Sahrir (tokoh gerakan perlawanan rahasia terhadap Jepang), Soekarno (kepala Negara masa Jepang, presiden RI), Van Dick (orang Belanda, tawanan Jepang, berlindung pada tentara Indo), Van Martin (orang Belanda, pengikut Nazi yang bekerjasama dengan Jepang), Kitajo dan Sahuti (keduanya orang Jepang yang ditawan pejuang Indonesia), dan tentara atau pengawal.

Para aktor drama tersebut ditampilkan melalui dialog-dialog drama dalam empat pembabakan. Babak pertama diawali dengan sebuah lagu puitis yang diperankan oleh Sulaiman. Lagu puitis tersebut adalah lagu bertema kemerdekaan yang dirindukan Sulaiman dengan nada kesedihan. Melalui dialog dengan Izzuddin, Sulaiman mengatakan bahwa lagu kesedihan tersebut muncul karena adanya kemiskinan dan penderitaan yang dialami oleh orang Indonesia. Lagu tersebut kemudian disambut dengan lagu jawaban oleh Izzuddin yang berusaha memberi dorongan pada Sulaiman bahwa kemerdekaan akan segera datang. Izzuddin mengatakan bahwa "Besok burung itu akan kembali//bebas merdeka ke sarangnya" (h. 10). Dialog tersebut terjadi di sebuah kamar yang remang disinari oleh lampu minyak redup. Sulaiman gelisah karena kekasihnya, Zainah, diduga menempuh pendidikan perawat. Menurutnya, pada gilirannya kekasihnya akan merawat orang-orang dan tentara Jepang yang dianggap sering berbuat asusila pada perawat pribumi.

Babak kedua berlokasi di rumah Haji Abdul Karim sekitar jam lima sore. Di babak ini terjadi dialog antara Abdul Karim, Hamidah, Aisyah, Otih, Majid dan Sulaiman. Dialog panjang terjadi antara Majid dan Sulaiman yang berdebat mengenai nasionalisme antara para pengikut Sahrir yang 
diwakili Sulaiman dan pengikut Soekarno yang diwakili Majid. Dalam perdebatan itu, Sulaiman memandang Majid dan para pengikut Soekarno telah bekerjasama dengan Jepang dan berusaha mempertahankan jabatan mereka. Sementara Majid berpendapat bahwa para pengikut Soekarno telah mengambil langkah politik cermat dengan diplomasi kemerdekaan yang memihak dan mengurangi korban perang fisik terhadap Jepang. Sementara kelompok Sahrir dipandang Majid terlalu beresiko karena mengorbankan nyawa penduduk sipil dengan pertempuran fisik yang tidak jelas ujung penyelesaiannya. Majid berpendapat bahwa secara fisik, tentara Indonesia belum mampu melawan penjajah sehingga perlu langkah diplomatis untuk meraihb kemerdekaan. Sementara Sulaiman tetap berdsikukuh bahwa perjuangan kemerdekaan harus direbut dengan peperangan fisik.

Babak ketiga kembali diawali dengan lagu puitis Sulaiman tentang kerinduan kemerdekaan Indonesia. Sulaiman bernyanyi sambil menahan luka yang bernanah. Di tempat ini pula Sahrir membaca pesan dari Soekarno agar Sahrir dan tentaranya menghentikan pemberontakan rahasia kepada Jepang agar mendapat persyaratan ringan dari sekutu. Secara lisan Soekarno berharap Sahrir bersedia menjadi kepala negara. Namun, Sahrir menolak dan justru mencalonkan Soekarno sebagai kepala negara jika kemerdekaan berhasil diraih. Selanjutnya, Sulaiman tetap menolak ajakan Soekarno menghentikan pemberontakan terhadap Jepang. Ketika mereka mendengar Jepang akan menyerah pada sekutu, Sulaiman dan tentaranya bergerak melakukan perampasan markas-markas tentara Jepang di pelosok Negeri.

Babak empat menceritakan peristiiwa yang terjadi pada tanggal 17 Agustus 1945 di rumah Abdul Karim dan di Lapangan Gambir. Suara 166 | ISSN: 22477-5150 http://journal.unesa.ac.id/index.php/jpi 
gelegar bom dan tembakan terjadi sejak pagi hari. Ribuan tentara nasional menyerang tentara Jepang yang menjaga lapangan Gambir. Akhirnya, tentara nasional berhasil menguasai markas-markas tentara Jepang dan mengumandangkan takbir dan kemerdekaan. Terjadilah konflik kepemimpinan antara pengikut Soekarno dengan pengikut Sahrir di mana masing-masing pengikut mengajukan pemimpin mereka masing-masing. Setelah keduanya, Soekarno dan Sahrir, berpidato dan mengajukan koleganya (Soekarno mengajukan Sahrir dan sebaliknya) terpilihlah Soekarno sebagai pemimpin negara.

Nasionalisme dalam 'Audat al-Firdaus

Empat babak drama 'Audat al-Firdaus menggambarkan bagaimana proses perebutan kemerdekaan Indonesia yang didorong oleh semangat nasionalisme (wațaniyah). Bagaimana semangat "nasionalisme" dalam merebut kemerdekaan muncul dalam drama 'Audat al-Firdaus? Yang pertama perlu diperjelas di sini adalah konsep nasionalisme itu sendiri. Sebagaimana kerangka pikir yang digunakan dalam penelitian ini, nasionalisme dilihat sebagai sebuah usaha membangkitkan aksi-aksi untuk mengumpulkan kelompok-kelompok yang beraneka ragam di bawah satu simbol entitas politik, pemerintahan, dan ekonomi sebuah bangsa (Yulia Nasrul Latifi dan Faruk, 2005). Secara umum kita dapat membatasi kata nasionalisme sebagai keinginan dan budaya bersama yang secara esensial merupakan pemaksaan umum budaya tinggi (high culture) pada masyarakat tertentu di mana budaya wong cilik (low culture) menjadi tunduk..." (Gellner, 1983: 56-57). Dalam konteks sastra, nasionalisme di sini akan ditempatkan sebagai cermin kehendak sastrawan yang memiliki 
kultur terjajah. Karena itulah lakon-lakon yang dimunculkan dalam kerangka budaya kolonial memiliki usaha-usaha untuk mengukuhkan identitas lokal.

Nasionalisme tidak hanya mengendap dalam tataran ide atausederhananya-semangat saja. Namun, nasionalisme menyatu dalam praktik-praktik keseharian individu dan tentu saja kelompok atau komunitas tertentu yang kemudian menjadi nation dari hasil kesamaan identitas atau tujuan tertentu. Praktik-praktik nasionalisme dalam 'Audat al-Firdaus ini lebih menonjolkan perjuangan fisik dan politik. Hampir sebagian besar tema dialog adalah perjuangan merebut kemerdekaan Indonesia baik di babak pertama, kedua, ketiga maupun terakhir. Nasionalisme di sini melekat dalam usaha merebut kebebasan kolektif atau kemerdekaan.

Loyalitas tokoh Sulaiman pada Sutan Sahrir demi mencapai kemerdekaan nasional menunjukkan bagaimana dia membentuk citra diri sebagai bagian (pejuang) dari pihak terjajah. Kenyataan yang dibentuk dari penjajahan yang tidak sesuai dengan nilai-nilai lokal dan semangat mengatur diri sendiri membuat tokoh Sulaiman merusaha keras meraih kemerdekaan lewat pertempuran sembunyi-sembunyi. Belum lagi perasaan cinta pada kekasihnya yang tertunda karena penjajahan. Dia berkali-kali menyanyikan lagu kerinduan pada kemerdekaan.

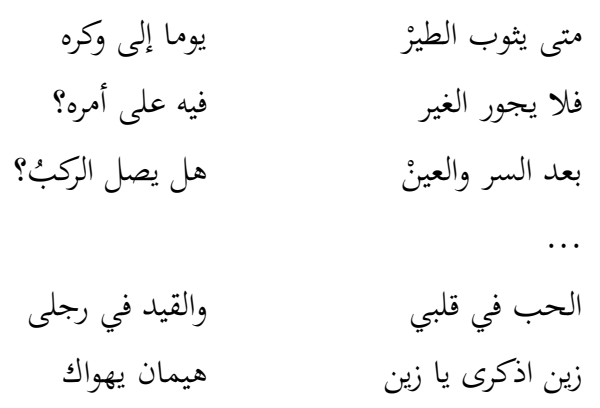


Mohammad Rokib, Kembalinya Surga Firdaus...(hal. 159-175)

('Audat al-Firdaus, h. 10 تحريه بالبين dan 88)

Frasa يثوب الطيز (kemerdekaan akan kembali) menunjukkan bagaimana tokoh Sulaiman mengharapkan sebuah kebebasan. Kebebasan dalam bait lagunya adalah kebebasan bagi dirinya sendiri agar perasaan kerinduan pada kekasihnya, Zainah, dapat terobati dan juga kemerdekaan tanah airnya تحرير مثواك) dapat segera diproklamasikan. Konteks kemerdekaan yang ditampilkan Sulaiman dapat ditempatkan pada dua tujuan. Pertama adalah tujuan pribadi yaitu keinginannya untuk segera menikah dengan Zainah, kekasihnya yang turut berjuang melawan penjajah yang menjadi pengikut Soekarno. Kedua, tujuan pribadi ini kemudian melebur dalam tujuan komunal yaitu kebebasan orang pribumi atas penjajahan. Untuk memenuhi kepentingan pribadi dan kepentingan komunal tersebut, maka usaha yang dilakukan adalah melawan penjajah untuk mengatur kehidupan bersama dengan orang-orang pribumi lainnya.

Kemerdekaan pada hakikatnya adalah bentuk dari sebuah kecintaan pada sesuatu. Pada kasus Sulaiman, ada dua persoalan cinta yang disampaikan secara tersirat pada babak pertama yaitu cinta pada kekasih dan cinta pada tanah air. Cinta pada kekasih dapat ditempatkan pada tataran individu sebagai manusia yang selalu membutuhkan rasa aman dan bahagia. Adapun cinta pada tanah air dapat ditempatkan pada tataran komunal di mana Sulaiman adalah bagian dari orang pribumi yang memiliki seperangkat tatanan nilai, imajinasi, tujuan, praktik-praktik lokal dan keinginan kolektif. Gellner (1983) menyebut tujuan-tujuan kolektif yang berangkat dan terakumulasi dari keinginan individu tersebut sebagai nasionalisme. 
Dalam kerangka nasionalisme sebagaimana yang diperankan oleh tokoh Sulaiman, tampak jelas kepentingan yang mucul dalam usaha meraih kemerdekaan. Dari kepentingan yang dimiliki, baik kepentingan individu maupun kolektif, telah muncul dan terbentuk identitas Sulaiman sebagai orang pribumi yang terjajah, termarginalisasi oleh penjajah, sehingga bersama dengan orang pribumi yang memiliki identitas sosial sama dengan para pejuang dan penduduk lainnya berusaha melakukan perlawanan.

Tokoh Sulaiman dalam drama 'Audat al-Firdaus memperlihatkan secara jelas perbedaan pandangannya tentang nasionalisme dengan para pengikut Soekarno seperti Majid dan Hamidah. Setelah berdebat mengenai penjajahan Jepang yang ditempatkan sebagai imbas perang dunia kedua, Sulaiman mempertanyakan visi nasionalisme para pengikut Soekarno dan membandingkannya dengan visi nasionalisme yang diusung oleh para pengikut Sahrir sebagaimana dirinya. Berikut ini dialog antara Sulaiman dan Majid (hal. 74).

$$
\begin{array}{r}
\quad \text { مليمان } \\
\text { ماجد }
\end{array}
$$

Dalam perebutan praktik nasionalisme antara Sulaiman sebagai pengikut Sahrir dan Majid sebagai pengikut Soekarno, keduanya berusaha menggambarkan praktik-praktik nasionalisme dalam pandangan masingmasing. Majid berusaha menempatkan gerakan politik yang diambil oleh pemimpinnya, Soekarno, adalah bentuk ideal nasionalisme untuk mencapai kemerdekaan. Majid berpendapat bahwa para pengikut Soekarno telah mengambil langkah politik cermat dengan diplomasi kemerdekaan yang memihak dan mengurangi korban perang fisik terhadap 170 | ISSN: 22477-5150 http://journal.unesa.ac.id/index.php/jpi 
Jepang. Sementara Sulaiman bersikukuh bahwa perjuangan fisik melawan penjajah yang ditempuh melalui strategi-strategi perang sebagaimana langkah Sahrir adalah bentuk sejati dari nasionalisme. Kelompok Sahrir dipandang Majid terlalu beresiko karena mengorbankan nyawa penduduk sipil dengan pertempuran fisik yang tidak jelas maknanya. Majid berpendapat bahwa secara fisik, tentara Indonesia belum mampu melawan penjajah sehingga perlu langkah diplomatis untuk meraih kemerdekaan. Soekarno menunggu perang dunia berakhir di samping pertimbangan bahwa Jepang semakin terdesak. Menurut Majid, jika para pejuang pribumi ikut berperang melawan Jepang, maka peperangan itu sia-sia karena langkah yang paling tepat bukan berperang secara fisik tetapi mempersiapkan generasi muda menguasai segala bidang untuk merebut kemerdekaan secara diplomatis terkait dengan kondisi perang dunia kedua.

Perdebatan mengenai praktik nasionalisme antara pengikut Sahrir dan Soekarno berakhir pada babak ketiga. Di babak ini Soekarno menulis surat secara tertulis pada Sahrir agar menghentikan penyerangan rahasia terhadap tentara Jepang. Dia mengusulkan Sahrir agar bersedia menjadi pemimpin negara kelak dan segera menyiapkan calon-calon anggota kabinet. Pesan tersebut disambut oleh Sahrir yang berjanji akan menghentikan penyerangan. Sahrir kemudian memerintahkan pada Sulaiman untuk berhenti melakukan penyerangan. Bagi Sulaiman, perintah Sahrir tersebut adalah kelemahan yang dianggap tunduk pada ultimatum Soekarno.

Dengan berbagai penjelasan rasional, Sahrir berusaha memberikan pemahaman pada Sulaiman tentang keputusan yang diambil. Salah satu 
alasan dari penghentian penyerangan adalah agar para pejuang siap melakukan penyerangan umum secara besar-besaran yang direncanakan pada 17 Agustus tahun 1945. Sulaiman tetap belum menerima alasan tersebut hingga pada akhirnya dia harus menerima keputusan Sahrir dengan keterpaksaan.

Tokoh Sulaiman dalam drama ini dihadirkan sebagai lakon yang berusaha memaknai nasionalisme. Sulaiman ditempatkan sebagai tokoh yang memiliki identitas pribumi. Dia bersama tokoh lain yang memiliki identitas sama (pribumi yang terjajah) berusaha melakukan perlawanan dan, pada saat yang sama, penyakralan bangsa agar bersatu. Jika kita lihat secara cermat, identitas yang dimiliki oleh Sulaiman sejatinya tidak tunggal alias multiidentitas. Identitas Sulaiman adalah Jawa, Islam dan terjajah. Dalam kondisi multiidentitas tersebut, dia berusaha membayangkan sebuah bayangan (imajinasi) yang menjalin hubungan dengan orang lain (Anderson, 2001). Meskipun dia berbeda dengan non-Jawa atau nonMuslim, namun berangkat dari identitas yang sama yaitu terjajah, dia berusaha memaknai kemerdekaan sebagai bayangan ideal kehidupannya.

Dalam praktik, Sulaiman memiliki berbedaan pandangan yang sangat jelas dengan pribumi terjajah lainnya seperti Seokarno dan pengikutnya, bahkan dengan Sahrir sebagai pemimpinnya. Dalam empat babak drama yang terdiri dari 103 halaman ini, Sulaiman digambarkan sebagai lakon yang menempatkan nasionalisme sebagai penegasan tujuan pribadi. Dia memperkuat karakter pribadinya sebagai aktor yang memaknai nasionalisme dengan perjuangan fisik. Kemerdekaan dimaknai sebagai tujuan yang dihasilkan melalui kemenangan fisik atau peperangan fisik. Nasionalisme sebagai perekat usaha perjuangan kemerdekaan disejajarkan dengan usaha-usaha fisik. 
Namun Bakathir, penulis drama ini, berusaha menyandingkan aktor Sulaiman dengan lakon-lakon lain yang berusaha memaknai nasionalisme secara lebih luas daripada sekadar usaha imajinasi kolektif kaum pribumi terjajah. Dari peran tokoh seperti Majid, Hamidah, Zainah, Abdul Karim dan Sahrir, karakter Sulaiman tertutupi oleh sikap para tokoh tersebut yang berusaha memaknai nasionalisme sebagai semangat pembebasan yang tidak hanya bisa diperoleh dengan cara fisik atau peperangan belaka.

Ketika tokoh Sahrir memerintahkan Sulaiman menghentikan perang atas instruksi Soekarno, terjadilah perubahan paradigma nasionalisme pada kelompok Sahrir. Nasionalisme yang awalnya ditempatkan pada posisi penyatuan kekuatan (fisik) berubah menjadi penyatuan strategi yang berusaha mewujudkan imajinasi kolektif yaitu kemerdekaan yang mendorong kemandirian institusi politik, ekonomi dan budaya. Melalui kemandirian dan otonomi kuasa yang disesuaikan dengan imajinasi kolektif orang pribumi, nasionalisme dimaknai sebagai ruang penyatuan identitas yang terbuka dan akan terus melahirkan makna-makna baru terkait dengan konsep kemerdekaan bagi kaum terjajah.

\section{SIMPULAN}

Drama 'Audat al-Firdaus yang ditulis oleh Bākathīr menunjukkan semangat nasionalisme yang merepresentasikan pribadinya. Semangat nasionalisme Bākathīr dapat dilihat dari tokoh-tokoh drama terutama Sulaiman dan Majid. Hal ini bisa dimaklumi karena dia terlahir di Surabaya, Indonesia. Sebagai negara yang menjadi tempat kelahirannya, 'Audat alFirdaus adalah ekspresi cinta Bākathīr terhadap Indonesia. 
Makna kehadiran tokoh Sulaiman yang memiliki karakter keras, teguh pendirian dan bersemangat merupakan simbol dari bentuk nasionalisme (ekstrim) saat itu. Sulaiman diposisikan sebagai tokoh yang memiliki identitas pribumi kuat. Namun, identitas Sulaiman sejatinya tidak tunggal karena dia juga memiliki multi identitas yang mengimajinasikan kemerdekaan sebagai sebuah imaji komunitas. Dalam kondisi ini, identitas yang beragam lebur menjadi sebuah kesatuan bayangan yaitu nasionalisme kelompok pribumi yang kemudian menjadi negara Indonesia.

Selain berusaha menonjolkan aktor yang memiliki nasionalisme (ekstrim) tersebut, Bākathīr menyandingkan aktor Sulaiman dengan aktor lain yang berusaha memaknai nasionalisme secara lebih luas daripada sekadar usaha imajinasi kolektif kaum pribumi terjajah. Adanya tokoh seperti Majid munjukkan bagaimana nasionalisme (ekstrim) Sulaiman melebur dalam sikap Majid yang berusaha memaknai nasionalisme sebagai semangat pembebasan yang tidak hanya bisa diperoleh dengan cara fisik atau peperangan belaka.

\section{DAFTAR RUJUKAN}

Anderson, Benedict O’G. 1991. Imagined Communities: Reflection on the Origin and Spread of Nationalism. London: Verso.

Badawi, M.M. "Islam in Modern Egyptian Literature", dalam Journal of Arabic Literature, Vol. 2 (1971), pp. 154-177.

Bākathīr, 'Ali Aḥmad. (tanpa tahun). 'Audatu al-Firdaus. Tanpa tempat: Dar Misr li al-Thiba'ah.

Gellner, Ernest. 1983. Nations and Nationalism. Itacha: Cornell University Press. 
Mohammad Rokib, Kembalinya Surga Firdaus...(hal. 159-175)

Hassim, Eeqbal. 2009. "The Significance of Qur'anic Verses in the Literature of Ali Ahmad Bākathīr: Case studies of Silsila wa al-Gufran and al-Duktur Hazim" dalam NCEIS Research Paper Vol. 1, No. 3.

Latifi, Yulia Nasrul dan Faruk. 2005. "Nasionalisme dalam an-Nidā'u alKhālid karya Najib Kaylani. Dalam Humanika, XVIII (1).

Starkey, Paul. 2006. Modern Arabic Literature. Edinburg: Edinburg University Press Ltd. 